\title{
Anal Adenocarcinoma within Anorectal Fistula
}

National Cancer Institute

\section{Source}

National Cancer Institute. Anal Adenocarcinoma within Anorectal Fistula. NCI Thesaurus. Code C7475.

An anal adenocarcinoma arising from the lining of an anorectal fistulous tract. The overlying anal mucosa does not show evidence of neoplastic changes. Some cases are associated with Crohn disease. 